\title{
種々な支持電解質溶液中におけるチタン (IV)の電極反応速度定数の測定
}

\author{
（昭 和 43 年 7 月 3 日受理）
}

田中一好・守、永健一・中埜邦夫*1

初期の I-F ポーラログラフにおいて用いられた回転スイッチのかわりにチョッパーを用いて改良した I-Fポーラログラフ装置 を製作した。この回路の周波数は 25 から $100 \mathrm{c} / \mathrm{s}$ まで変えることができた。高い周波数の場合，ク形波ポーラログラフィーに対 する松田式からピーク電流と速度定数との関倸を導いた。測定したピーク電流から，この式を用いて計算した種々の支持電解質中 の亜鉛（II）の速度定数は交流インビーダンス法により測定した值とかなり一致した。したがって，本回路は準可逆の電極反応速度 定数を測定するのに有効であると考えられる。この方法を種々の酸の溶液におけるチタン( N)の速度定数を測定するのに用いた。 六られた結果のいくつかの值はつぎのようになる。酒石酸 $(1 \mathrm{~mol} / l)$ では $k_{\mathrm{s}}$ は $2.2_{6} \times 10^{-3} \mathrm{~cm} / \mathrm{sec}$, 硫酸 $(8 \mathrm{~mol} / l)$ では $3.99 \times 10^{-3}$ $\mathrm{cm} / \mathrm{sec}$ シュウ酸 $(0.1 \mathrm{~mol} / \mathrm{l})+$ 臭化カリウム $(0.2 \mathrm{~mol} / l)$ では $6.6_{6} \times 10^{-3} \mathrm{~cm} / \mathrm{sec}$ である。

\section{1 緒言}

回転スイッチのかわりにチョッパーを用いる方式の I-F ポーラ ログラフ回路を自作し，これを用いて種々の支持電解質溶液にお けろチタン $(\mathbb{N})$ - (I ) の電子授受反応の標準電位における電極反 応速度定数 $k_{\mathrm{s}}$ を求めた。現在まで, 滴下水銀電極における $k_{\mathrm{s}}$ は 酒石酸溶液については多くの測定結果1) 3)があり，シュウ酸溶液 については Smith4)により測定されているので比較検討した。チ タン (II) は硫酸濃度が高い場合, 可逆度の比較的大きな I-F ポー ラログラムがえられるので硫酸濃度を变えて直流ポーラログラフ 法により移動係数と拡散定数を求め, 改良した I-F ポーラログラ ムの平均ピーク電流值から $k_{\mathrm{s}}$ を求めた結果について郝告する。

\section{2 試薬および装置}

\section{1 試 薬}

チタン $(\mathbb{P})$ の 溶液は特級ヘキサフルオロチタン酸 カリム約 $2.5 \mathrm{~g}$ に濃硫酸を加えゆるやかに熱して溶解させ, 放冷後蒸留水 で $250 \mathrm{~m} l$ にし約 $0.02 \mathrm{~mol} / l$ 貯蔵液とした。この溶液の一部を とりシュウ酸溶液中で直流ポーラログラフ法により濃度を決定し た。その他の試薬溶液は特級試薬から調製した。

\section{2 装}

I-F ポーラログラフ法5) とは, 微小の電圧差のある直流電圧を 交互に電極にかけ，その電位の差による電解電流の差を記録する 方法である。この装置が製作された当時は電圧を交互にかけるた め回転スイッチを用いたが，今回改良した部分は回転スイッチの かわりにチョッパーを用い, 市販の交流発振器からの交流を自作 の増幅器で増幅してその駆動電源 $(6.3 \mathrm{~V})$ としたことである。こ の装置を図 1 に示した。発振器の発振周波数を変えるとチョッパ

*1 Kazuyoshi Tanaka, Ken-ichi Morinaga, Kunio NAKANO 立教大学理学部化学教室, 東京都豊島区西池 袋

1) J. E. B. Randles, K. W. Somerton, Trans. Faraday Soc., 48, 973(1952).

2) P. Delahay, I. Tratchenberg, J. Am. Chem. Soc., 80, 2094(1958).

3) H. A. Laitinen, K. Eda, M. Nakanishi, Talanta, 11, 321 (1964).

4) D. E. Smith, Anal. Chem., 35, 610(1963).

5) M. Ishibashi, T. Fujinaga, Bull. Chem. Soc. Japan, $25,68,238(1952)$.
一の断続周波数が変化し，ク形波ポーラログラフ法においでク形 波の周波数を変化させた場合と同じ効果をもたせることができ る。発振器恃東亜電波製広帯域発振器 CR-10 KB 型, 記録計は 柳本製ガルバレコーダー G A-103 型, 加電圧装置も柳本製写真 式ポーラログラフの加電圧部を用いた。測定用セルは柳本製電解 びん P-1 B 型を用い，対極は水銀池とした。微小電圧差として $10 \mathrm{mV}(2 \Delta E)$ を使用した。

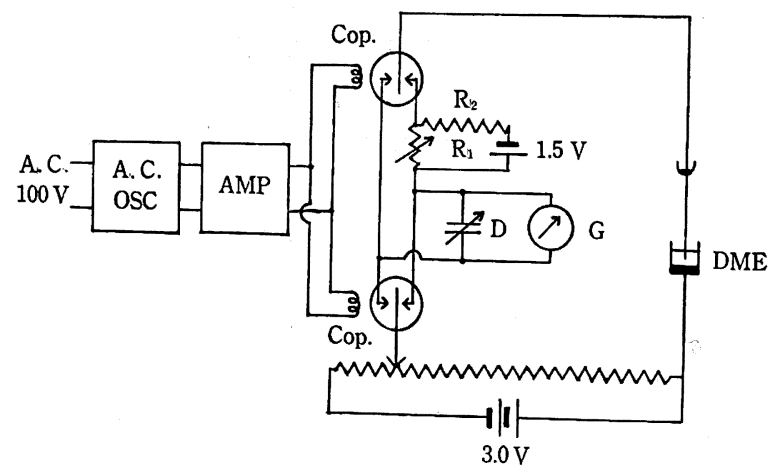

A. C. OSC: 交流発振器, AMP: 低周波増幅器, Cop.: チョ ッパー, $\mathrm{R}_{1}: 100 \Omega, \mathrm{R}_{2}: 1.5 \mathrm{k} \Omega, \mathrm{D}:$ ダノビングコンデン サ $100 \mu \mathrm{F}, \mathrm{G}:$ ガルドレコーダー, DME：滴下水銀電極 図 1 改良した I-F ポーラログラフ回路

\section{3 実験結果と考察}

\section{$3.1 \boldsymbol{k}_{\mathrm{s}}$ の求め方}

I-F ポーラログラフ法の理論式は神原6) により可逆系について 与えられているが，準可逆系，非可逆系にも適用できるのは松田 のク形波ポーラログラフィーについての理論式》であり，つぎの ようになる。

$$
\begin{aligned}
& i=n \boldsymbol{F} q(\tau) D_{\mathrm{Ox}}^{1 / 2} C_{\mathrm{Ox}}^{*}\left(\frac{n \boldsymbol{F}}{\boldsymbol{R} T} \Delta E\right) \\
& \times \Theta^{-1 / 2} \bar{F}(\lambda \sqrt{\tau}) \overline{\boldsymbol{\varphi}}_{\text {recht }}(\lambda \sqrt{\Theta / 2 \pi}) \\
& \text { ここで } \\
& \bar{F}(\lambda \sqrt{\tau})=\frac{1}{4 \cosh ^{2}(\zeta / 2)}\left\{\frac{3}{5}\right. \\
& \left.-2 \sqrt{\frac{3}{7 \pi}}(\alpha \exp (-\zeta)-\beta) \frac{1}{1.13+\lambda \sqrt{\tau}}\right\}
\end{aligned}
$$

6) T. Kambara, Bull. Chem. Soc. Japan, 27, 529(1954).

7) H. Matsuda, Z. Elektrochem., 62, 977(1958). 


$$
\begin{gathered}
\bar{\varphi}_{\text {recht }}(\lambda \sqrt{\Theta / 2 \pi})=\frac{32}{\sqrt{2 \pi}{ }_{\mu=1}^{\infty} \frac{1}{\sqrt{2 \mu-1}^{3}}} \\
\times \frac{1+\sqrt{2 \mu-1} /(\lambda \sqrt{\Theta / 2 \pi})}{1+[1+\sqrt{2 \mu-1} /(\lambda \sqrt{\Theta / 2 \pi})]^{2}} \\
\lambda=\frac{k_{\mathrm{s}}}{\sqrt{D}}(\exp (-\alpha \zeta)+\exp (\beta \zeta)), \zeta=\frac{n \boldsymbol{F}}{\boldsymbol{R} T}\left(E-E_{1 / 2}^{r}\right)
\end{gathered}
$$

i はク形波ポーラログラフ法における平均電流值， $D_{\mathrm{Ox}}, D_{\mathrm{Red}}$ はおのおの酸化体, 還元体の拡散定数, $D=D_{\mathrm{Ox}}^{\beta} \cdot D_{\mathrm{Red}}^{\alpha}, C_{\mathrm{Ox}}^{*}$ は 酸化体の母液濃度, $\tau$ は水銀の滴下時間, $q(\tau)$ は $\tau$ 秒における水 銀滴の表面積, $\Delta E$ はク形波電圧の振幅, $k_{\mathrm{s}}$ は標準電位における 電極反応速度定数, $\Theta$ はク形波の半周期, $E_{1 / 2}^{r}$ は可逆半波電位, $\alpha, \beta$ はおのおの還元反応酸化反応の移動係数である。ただし $\lambda$ に おいては活量係数を 1 とした。 ク形波の周波数 $f$ と $\Theta$ とは $\Theta=$ $1 /(2 f)$ なる 関係にあり，いま周波数が高い場合，すなわち， $\sqrt{2 \mu-1} /(\lambda \sqrt{\Theta / 2 \pi}) \gg 1 * 2$ のとき(3)式はつぎのように近似 できる。

$$
\begin{aligned}
\bar{\varphi}_{\text {recht }} & (\lambda \sqrt{\Theta / 2 \pi}) \\
= & \frac{32}{\sqrt{2 \pi}^{3}} \sum_{\mu=1}^{\infty} \frac{1}{\overline{\sqrt{2 \mu-1}}^{3}} \frac{1}{\sqrt{2 \mu-1} /(\lambda \sqrt{\Theta / 2 \pi})} \\
= & \lambda \sqrt{\Theta}
\end{aligned}
$$

(4)式を(1)式に代入すると $\Theta$ を含まない次式がえられる。

$$
i \fallingdotseq n \boldsymbol{F} q(\tau) D_{\mathrm{Ox}}^{1 / 2} C_{\mathrm{Ox}}^{*}\left(\frac{n \boldsymbol{F}}{\boldsymbol{R} T} \Delta E\right) \lambda \bar{F}(\lambda \sqrt{\tau})
$$

ここで (2)式のカッコ内の第 2 項は第 1 項にくらべて小さい值 となるので*3, (5) 式における $\lambda \bar{F}(\lambda \sqrt{\tau})$ を $3 / 5 \cdot k_{\mathrm{s}} / \sqrt{D} \cdot(\exp$ $(-\alpha \zeta)+\exp (\beta \zeta)) / 4 \cosh ^{2}(\zeta / 2)$ と近似し，これをらについて微 分してピーク電位 $E_{\mathrm{p}}$ を求めると

$$
\zeta=\frac{n \boldsymbol{F}}{\boldsymbol{R} T}\left(E_{\mathrm{p}}-E_{1 / 2}^{r}\right)=\ln \frac{\beta}{\alpha}
$$

となり，この関係を(5)式に代入すると平均ピーク電流值 $i_{\mathrm{p}}$ は つぎのようになる。

$$
\begin{aligned}
& \bar{\imath}_{\mathrm{p}} \fallingdotseq n \boldsymbol{F} q(\tau)\left(\frac{D_{\mathrm{Ox}}}{D_{\mathrm{Red}}}\right)^{1 / 2} C_{\mathrm{Ox}}^{*}\left(\frac{n \boldsymbol{F}}{\boldsymbol{R} T} \Delta E\right) \\
& \times k_{\mathrm{s}} \alpha^{\alpha} \beta^{\beta} \bar{G}(\lambda \sqrt{\tau}) \\
\text { ここで } &
\end{aligned}
$$

$$
\begin{aligned}
& \bar{G}(\lambda \sqrt{\tau})=\frac{3}{5} \\
& \quad+2 \sqrt{\frac{3}{7 \pi}} \frac{2 \alpha-1}{\beta} \frac{1}{1.13+k_{\mathrm{s}} \alpha^{-\beta} \beta^{-\alpha} \sqrt{\tau} / \sqrt{D}}
\end{aligned}
$$

(7)式は $\Theta$ の項を含んでいないので周波数が変化しても $i_{\mathrm{p}}$ は一 定であり, 拡散定数, 移動係数の值がわかっていれば，実測の $i_{\mathrm{p}}$ から $k_{\mathrm{S}}$ を計算できる。本実験では $D=D_{\mathrm{Ox}}=D_{\mathrm{Red}}$ とし， Illkovič 式8) 用いて拡散電流值から拡散定数を求めた。移動係

*2 $\sqrt{2 \mu-1} /(\lambda \sqrt{\Theta / 2 \pi})$ は $\mu=1$ のときもっとも小さい值と なり，乙のとき上記の条件は周波数として $f \gg k_{\mathrm{s}}{ }^{2}$ $\times(\exp (-\alpha \zeta)+\exp (\beta \zeta))^{2} / 4 \pi D$ で表わされる. いま $\alpha$ $=0.5, D=5 \times 10^{-6} \mathrm{~cm}^{2} / \mathrm{sec}, k_{\mathrm{s}}=10^{-2} \mathrm{~cm} / \mathrm{sec}$ とした場 合, $f \gg 6.4 \mathrm{c} / \mathrm{s}$ となり, 実際に $f=64 \mathrm{c} / \mathrm{s}$ 以上ではこの 条件がなり立っていると考兄られる。

*3 $1 \mathrm{~mol} / l$ 塩化カリウムでの亜鉛(II)の場合, 第 2 項は 0.053 であり, 今回測定した $k_{\mathrm{s}}$ のもっとも小さい $5.5 \mathrm{~mol} / l$ 硫酸と $0.5 \mathrm{~mol} / l$ 硫酸ナトリウムでのチタン(IV)の場合, 0.081 である.よって $\alpha$ が $0.3 \sim 0.7$ 程度では第 2 項は 第 1 項の $3 / 5$ よりなり小さい值となるので電位を考兑 るときは無視した。
数 $\alpha$ は非可逆系では, 直流ポーラログラムの逆対数プロットの傾 斜から次式を用いて計算される9)。

$$
\alpha=-2.3 \frac{\boldsymbol{R} T}{n \boldsymbol{F}}\left(\frac{\Delta \log i /\left(\bar{i}_{\mathrm{d}}-i\right)}{\Delta E}\right)
$$

しかし非可逆系では I-F ポーラログラムはえられない。準可逆 系では，電極電位が平衡電位より十分院側にずれると逆反応がお さえられて逆対数プロットが直線となり，その傾斜から(9)式を 用いて $\alpha$ が計算でさる。可逆系では，容易には $\alpha$ が求まらないの で本実験での $k_{\mathrm{s}}$ の測定は準可逆系にかぎられてしまう。

\section{-3.2 測定法の検討}

発振器からの周波数を高くした場合, 商業周波数用のチョッパ 一とガルバレコーダーを組み合わせた装置がどこまで正常に作動 するかを $1 \mathrm{~mol} / l$ 塩化カリウム溶液中における $1 \times 10^{-3} \mathrm{~mol} / l$ 力 ドミウム (II)について I-F ポーラログラムをとってみた。この系 は可逆系なので松田の式7により $i_{\mathrm{p}} \propto f^{1 / 2}$ なる関係があり, 周 波数変化によるチョッパーの作動を試験するのに都合がよい。そ の結果を表 1 に示す。表 1 における計算值は $f=50 \mathrm{c} / \mathrm{s}$ での平均 ピーク電流值を基準とし周波数の平方根に比例するとして計算し た值である。その結果 $100 \mathrm{c} / \mathrm{s}$ までは本装置が正常に作動するこ とが認められるが, $150 \mathrm{c} / \mathrm{s}$ では $\bar{\imath}_{\mathrm{p}}$ が小さくなった。これはチョ ッパーが追随できなかったというよりも記録計の周波数变化に対 寸る応答が供わなかったためであろう*4。

表 1 平均ピーク電流值と周波数との関係

$\mathrm{Cd}(\mathbb{I}): 1 \times 10^{-3} \mathrm{~mol} / l, \mathrm{KGl}: 1 \mathrm{~mol} / l$

\begin{tabular}{ccc} 
& \multicolumn{2}{c}{ 平均ビーク電流值 $(\mathrm{cm})$} \\
\cline { 2 - 3 } & 実 測 $(\mathrm{c} / \mathrm{s})$ & 值 \\
50 & 7.95 & 7.95 \\
80 & 10.35 & 10.06 \\
100. & 11.50 & 11.24 \\
150 & 3.60 & 13.77
\end{tabular}

亜鉛（II）の塩化カリウム溶液について I-F ポーラログラフ法 により平均ピーク電流值の測定を行なった。記録計の感度 0.010 $\mu \mathrm{A} / \mathrm{mm}$ ，ダンピングコンデンサ $100 \mu \mathrm{F}$ としたときの測定周波 数と $i_{\mathrm{p}}$ とを表 $2 \mathrm{~A}$ に示してある。 $\overline{\mathrm{p}}_{\mathrm{p}}$ はほば一定と考えられるの で， $74 \mathrm{c} / \mathrm{s}$ での $i_{\mathrm{p}}$ の值から (7)式を用いて計算した $k_{\mathrm{s}}$ は表 2 B に示されているとおり交流インピーダンス法による值 ${ }^{10)}$ と致 した。そこで硝酸カリウム，臭化カリウム溶液において，記録計 の同じ条件で測定した $i_{\mathrm{p}}\left(\right.$ 表 $2 \mathrm{~A}$ ) から求めた $k_{\mathrm{s}}$ の值と交流イン ピーダンス法による文献值とを表 $2 \mathrm{~B} に$ 示した。いずれもよい一 致がえられたので，本実験における準可逆系の $k_{\mathrm{s}}$ の測定法は有 効であると考えられ，以下の実験では感度とダンピングコンデン サを上述の值に設定した。塩化カリウム溶液においては拡散律速

8) I. M. Kolthoff, J. J. Lingane, "Polarography", In-, terscience, New York(1952)p. 63.

9) H. Matsuda, Y. Ayabe, Bull. Chem. Soc. Japan, 28, 422(1955).

*4 チョッパーが $150 \mathrm{c} / \mathrm{s}$ で駆動可能なことはオッシロスコ ープで確かめた. したがって，150 c/s ではガルバレコ ーダーが微小電圧差による電解電流の差を示さないため であると考えられる。

10) J. E. B. Randles, K. W. Somerton, Trans. Faraday Soc., 48, 951 (1952). 
と思わ机る限界電流を示すので逆刘数プロットから求めた $\alpha=$ 0.29 忩用いて $k_{\mathrm{s}}$ を計算したが，その他の溶液での $\alpha$ は交献值 ${ }^{11}$ を用い， $D$ は $7.2 \times 10^{-6} \mathrm{~cm}^{2} / \mathrm{sec}$ とした。表 2 から臭化力リウ 么溶液において可逆系の $k_{\mathrm{S}}\left(>10^{-2} \mathrm{~cm} / \mathrm{sec}\right)$ に近い值 $\left(8.0 \times 10^{-3}\right.$ $\mathrm{cm} / \mathrm{sec}$ )が測定できたので, 本実験の I-F ポーラログラフ法に より $k_{\mathrm{s}}$ が $10^{-2} \mathrm{~cm} / \mathrm{sec}$ 程度までの系について測定可能であるこ とがわかった。

\begin{tabular}{|c|c|c|}
\hline \multicolumn{3}{|c|}{$\begin{array}{l}\text { 典鉛 (I) の測定周波数と平均ピーク電流值 } \\
\mathrm{Zn}(\mathbb{I}): 4.5 \times 10^{-4} \mathrm{~mol} / l\end{array}$} \\
\hline 支持電解質 & 周波数 $(\mathrm{c} / \mathrm{s})$ & 平均ビーク電流值 $(\mu \mathrm{A})$ \\
\hline$l \mathrm{~mol} / l \mathrm{KCl}$ & $\begin{array}{l}40 \\
60 \\
74\end{array}$ & $\begin{array}{l}0.80_{4} \\
0.82_{0} \\
0.82_{0}\end{array}$ \\
\hline $1 \mathrm{~mol} / l \mathrm{KNO}_{3}$ & $\begin{array}{l}40 \\
70\end{array}$ & $\begin{array}{l}0.73_{0} \\
0.72_{3}\end{array}$ \\
\hline $1 \mathrm{~mol} / l \mathrm{KBr}$ & $\begin{array}{l}40 \\
74\end{array}$ & $\begin{array}{l}1.30_{2} \\
1.40_{6}\end{array}$ \\
\hline
\end{tabular}

表 $2 \mathrm{~B}$ 亜鉛 (II)の速度定数 $\left(20^{\circ} \mathrm{C}\right)$

\begin{tabular}{|c|c|c|c|c|c|}
\hline \multirow{2}{*}{$\begin{array}{l}\mathrm{Zn}(\mathbb{I}) \text { の濃度 } \\
\left(\times 10^{-4} \mathrm{~mol} / l\right)\end{array}$} & \multirow{2}{*}{$\begin{array}{c}\text { 支 持 } \\
\text { 電解質 } \\
(1 \mathrm{~mol} / l)\end{array}$} & \multirow{2}{*}{$\begin{array}{l}\text { 周波数 } \\
(\mathrm{c} / \mathrm{s})\end{array}$} & \multirow{2}{*}{$\begin{array}{l}\text { 移動 } \\
\text { 係数11) }\end{array}$} & \multicolumn{2}{|c|}{$\begin{array}{c}\text { 速 度 定 数 } \\
\left(\times 10^{-3} \mathrm{~cm} / \mathrm{sec}\right)\end{array}$} \\
\hline & & & & 測定值 & 交献值 ${ }^{10}$ \\
\hline $\begin{array}{l}2.2 \\
4.5\end{array}$ & $\underset{1 "}{\mathrm{KGl}}$ & $\begin{array}{l}74 \\
74\end{array}$ & $\begin{array}{l}0.29 \\
0.29\end{array}$ & $\begin{array}{l}3.9 \\
4.0\end{array}$ & 4.0 \\
\hline 4.5 & $\mathrm{KNO}_{3}$ & 70 & 0.39 & 3.6 & 3.5 \\
\hline $\begin{array}{l}4.0 \\
4.5\end{array}$ & $\underset{\prime \prime}{\mathrm{KBr}}$ & $\begin{array}{l}74 \\
74\end{array}$ & $\begin{array}{l}0.36 \\
0.36\end{array}$ & $\begin{array}{l}8.0 \\
8.3\end{array}$ & 8.0 \\
\hline
\end{tabular}

\section{3 チタン $(\mathrm{IV})$ の $\boldsymbol{k}_{\mathrm{s}}$ の測定}

種々な支持電解質溶液中における $k_{\mathrm{s}}, \alpha$ および $D$ の測定結果 を表 3 にあげてある。

酒石酸溶液中におけるチタン $(\mathbb{N})$ の $k_{\mathrm{s}}$ は交流インピーダンス 法により測定され，Randles ら, Delahay ら²)，そして Laitinen ら゙) はおのおの $9.0 \times 10^{-3}, 4.1 \sim 7.2 \times 10^{-3}, 1.74 \times 10^{-3} \mathrm{~cm} / \mathrm{sec}$ と異なった値を報告している。Delahayらの $k_{\mathrm{s}}$ は $1 \mathrm{~mol} / l$ 酒石 酸と $0.1 \mathrm{~mol} / l$ 塩化ナトリウム溶液におけるるのであり，チタン II）-チタン $(\mathbb{N})$ の濃度比を一定にし全濃度を変化させると $k_{\mathrm{s}}$ が
変わることが指摘されている。Laitinen らの値は $1 \mathrm{~mol} / l$ 酒石酸 と $0.2 \mathrm{~mol} / l$ 硫酸ナトリウム溶液中におけるものであり，本測定 值とほぼ同じ值である。したがって $k_{\mathrm{s}}$ はチタン(N)の濃度およ び化学種の違いにより異なったのであろう。著者らが直流ポーラ ログラムの逆対数プロットから求めた $\alpha(0.48)$ はaitinen らの $0.48_{8}$ とも一致している。

硫酸溶液の場合は硫酸濃度が $4 \mathrm{~mol} / l$ 以下での直流ポーラログ ラムは非可逆となり I-F ポーラログラムはえられない。表 3 にお いて硫酸濃度が高いほど $k_{\mathrm{s}}$ が大きくなり電極反応は可逆に近づ き，硫酸浱度の変化により $\alpha$ が極端に変化することが認められチ タン ( IV)の化学種が硫酸濃度により変わるものと思われる。これ を裏づけるものとして硫酸溶液中での直流ポーラログラフ法によ る研究12)からチタン $(\mathbb{N})$ はつぎのような平衡にあり，可逆の電極 反応は $\left[\mathrm{Ti}\left(\mathrm{OH}_{2}\right) \mathrm{SO}_{4}\right]^{2+}$ によるものであろうという報告がある。

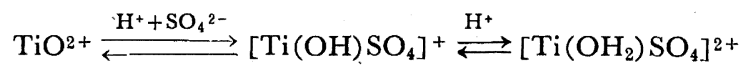

シュウ酸溶液中でのチタン ( N) の直流ポーラログラムの逆刘数 プロットの傾斜は $60 \sim 64 \mathrm{mV}$ となり，電極反応は一電子可逆反 応となり $\alpha$ を求めることができなかった。I-F ポーラログラフ法 による本実験法では周波数を変えるとピーク電流值が変化し；た とえばシュウ酸とシュウ酸カリウム溶液で $f$ を 37 から $74 \mathrm{c} / \mathrm{s}$ に すると $i_{\mathrm{p}}$ は $1.38_{7}$ から $1.70_{6} \mu \mathrm{A}$ となり，（7)式を用いて $k_{\mathrm{s}}$ を 計算できない。 $\left.\mathrm{Smith}^{4}\right)$ にると $0.2 \mathrm{~mol} / l$ シュウ酸溶液での $k_{\mathrm{s}}$ は $4.6 \times 10^{-2} \mathrm{~cm} / \mathrm{sec}$ であり， $\alpha, D_{\mathrm{Ox}}$ はおのおの $0.36,4.6 \times$ $10^{-6} \mathrm{~cm}^{2} / \mathrm{sec}$ であり，この值を(4) 式の条件式に入れると $f 》$ $2.4 \times 10^{3} \mathrm{c} / \mathrm{s}$ となり, 本装置での $f=100 \mathrm{c} / \mathrm{s}$ 程度では $k_{\mathrm{s}}$ を求め ることができない。したがって,表 3 にあげてある $k_{\mathrm{s}}$ の值は $\alpha=$ 0.5 と仮定し, 実測の $D=5.0 \times 10^{-6} \mathrm{~cm}^{2} / \mathrm{sec}$ を用いて $f=74$ $\mathrm{c} / \mathrm{s}$ での $i_{\mathrm{p}}$ から求めた值である。ただし臭化カリウムを加えた 溶液では $f$ を変えても $i_{\mathrm{p}}$ が変化しないので $(7)$ 式から $k_{\mathrm{s}}$ を求 めた。シュウ酸溶液に硫酸カリウム, 塩化カリウムおよび臭化カ リウムを加えたのは，各陰イオンによる $k_{\mathrm{s}}$ の变化を調べるため であったが，臭化カリウムの場合を除いて比較できる結果はえら れなかった。

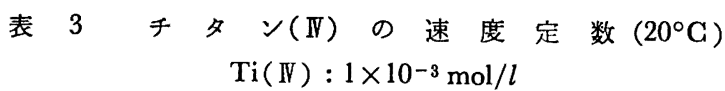

支持電解質

$1 \mathrm{~mol} / l \underset{1}{\mathrm{CH}}(\mathrm{OH}) \mathrm{CO}_{2} \mathrm{H}$

$8 \mathrm{~mol} / l \quad \mathrm{H}_{2} \mathrm{SO}_{4}$

$6 \mathrm{~mol} / l \quad \mathrm{H}_{2} \mathrm{SO}_{4}$

$5.5 \mathrm{~mol} / l \quad \mathrm{H}_{2} \mathrm{SO}_{4}+0.5 \mathrm{~mol} / l \mathrm{Na}_{2} \mathrm{SO}_{4}$

$0.5 \mathrm{~mol} / l\left(\mathrm{CO}_{2} \mathrm{H}\right)_{2}$

$0.1 \mathrm{~mol} / l\left(\mathrm{CO}_{2} \mathrm{H}\right)_{2}$

$0.05 \mathrm{~mol} / l\left(\mathrm{CO}_{2} \mathrm{H}\right)_{2}+0.05 \mathrm{~mol} / l\left(\mathrm{CO}_{2} \mathrm{~K}\right)_{2}$

$0.1 \mathrm{~mol} / l\left(\mathrm{CO}_{2} \mathrm{H}\right)_{2}+0.1 \mathrm{~mol} / l \mathrm{~K}_{2} \mathrm{SO}_{4}$

$0.1 \mathrm{~mol} / l\left(\mathrm{CO}_{2} \mathrm{H}\right)_{2}+0.2 \mathrm{~mol} / l \mathrm{KCl}$

$0.1 \mathrm{~mol} / l\left(\mathrm{CO}_{2} \mathrm{H}\right)_{2}+0.2 \mathrm{~mol} / l \mathrm{KBr}$

$\begin{array}{ccccc}\text { 移動係数 } & \text { 拡散定数 }\left(\times 10^{-6} \mathrm{~cm}^{2} / \mathrm{sec}\right) & \text { 周波数 }(\mathrm{c} / \mathrm{s}) & i_{\mathrm{p}}(\mu \mathrm{A}) & \text { 速度定数 }(\mathrm{cm} / \mathrm{sec}) \\ 0.48 & 2.0 & 37 & 0.31_{8} & \\ & & 74 & 0.31_{2} & 2.2_{6} \times 10^{-3} \\ 0.66 & 1.3 & 37 & 0.37_{4} & \\ & & 74 & 0.40_{0} & 3.9_{9} \times 10^{-3} \\ 0.75 & 2.0 & 30 & 0.18_{9} & \\ & & 60 & 0.19_{0} & 1.9_{0} \times 10^{-3} \\ 0.34 & 1.5 & 74 & 0.08_{2} & 0.8_{2} \times 10^{-3} \\ 0.50 & 5.0 & 37 & 1.36_{7} & \\ & & 74 & 1.69_{8} & >1.5_{8} \times 10^{-2} \\ 0.50 & 5.0 & 74 & 1.81_{3} & >1.6_{5} \times 10^{-2} \\ 0.50 & 5.0 & 37 & 1.39_{8} & \\ & & 74 & 1.70_{6} & >1.4_{1} \times 10^{-2} \\ 0.50 & 5.0 & 74 & 1.87_{0} & >1.7_{1} \times 10^{-2} \\ 0.50 & 5.0 & 74 & 1.68_{6} & >1.5_{4} \times 10^{-2} \\ 0.50 & 5.0 & 37 & 0.71_{6} & \\ & & 74 & 0.72_{8} & 6.6_{6} \times 10^{-2}\end{array}$

12) G. H. M. Habashy, Z. Anorg. Allg. Chem., 306, 312 (1960).
11) N. Tanaka, R. Tamamushi, Electrochimica Acta, 9, 963(1963). 